\title{
Development of High Temperature SiC Based Hydrogen/Hydrocarbon Sensors with Bond Pads for Packaging
}

Jennifer C. Xu ${ }^{1, a}$, Gary W. Hunter ${ }^{1, b}$, Liangyu Chen ${ }^{2, c}$, Azlin M. Biaggi-Labiosa ${ }^{1, d}$, Benjamin J. Ward ${ }^{3, \mathrm{e}}$, Dorothy Lukco ${ }^{4, \mathrm{f}}$, Jose M. Gonzalez III ${ }^{5}$,

Peter S. Lampard ${ }^{6}$, Michael A. Artale ${ }^{6}$, and Christopher L. Hampton ${ }^{6}$

${ }^{1}$ NASA Glenn Research Center (GRC), 21000 Brookpark Road, MS 77-1, Cleveland, OH 44135, USA

${ }^{2} \mathrm{OAI}$ / NASA GRC, 21000 Brookpark Road, MS 77-1, Cleveland, OH 44135, USA

${ }^{3}$ Makel Engineering, Inc., 15505 Neo Parkway, Cleveland, OH 44128

${ }^{4}$ ASRC Aerospace, NASA GRC, 21000 Brookpark Road, MS 77-1, Cleveland, OH 44135, USA

${ }^{5}$ Gilcrest, NASA GRC, 21000 Brookpark Road, MS 77-3, Cleveland, OH 44135, USA

${ }^{6}$ Sierra Lobo, NASA GRC, 21000 Brookpark Road, MS 77-3, Cleveland, OH 44135, USA

aJennifer.C.Xu@nasa.gov, 'aary.W.Hunter@nasa.gov, 'Liangyu.Chen-1@nasa.gov, dAzlin.M.Biaggi-Labiosa@nasa.gov, ${ }^{\mathrm{d} b w a r d @ m a k e l e n g i n e e r i n g . c o m, ~}{ }^{\mathrm{f}}$ Dorothy.Lukco@nasa.gov

Keywords: Hydrogen/hydrocarbon sensors, SiC, high temperature, Schottky diodes

Abstract: This paper describes efforts towards the transition of existing high temperature hydrogen and hydrocarbon Schottky diode sensor elements to packaged sensor structures that can be integrated into a testing system. Sensor modifications and the technical challenges involved are discussed. Testing of the sensors at $500^{\circ} \mathrm{C}$ or above is also presented along with plans for future development.

Silicon carbide ( $\mathrm{SiC}$ ) has shown great potential for harsh environment sensor applications. The NASA Glenn Research Center has previously demonstrated prolonged stable operation of gas sensing SiC-based Schottky diodes at elevated temperatures. These Schottky diodes use palladium oxide $\left(\mathrm{PdO}_{\mathrm{x}}\right)$ as a barrier layer between a catalytic precious metal, such as $\mathrm{Pd}$ or $\mathrm{Pt}$, and the $\mathrm{SiC}$ substrate. The $\mathrm{PdO}_{\mathrm{x}}$ barrier layer is intended to prevent silicide-forming reactions between the precious metal and the $\mathrm{SiC}[1,2]$. Testing has shown a $\mathrm{Pd} / \mathrm{PdO}_{\mathrm{x}} / \mathrm{SiC}$ structure provides stable sensing of hydrogen $\left(\mathrm{H}_{2}\right)$ and hydrocarbons $\left(\mathrm{C}_{\mathrm{x}} \mathrm{H}_{\mathrm{y}}\right)$ at high temperatures, while also being operational over a wide temperature range. For example, such a sensor was tested at $450^{\circ} \mathrm{C}$ for nearly $1500 \mathrm{hrs}$, and detection of hydrogen from room temperature to $500^{\circ} \mathrm{C}$ was also demonstrated $[1,2]$. The measurement of hydrogen down to the level of $250 \mathrm{ppb}$ in air was also achieved [2].

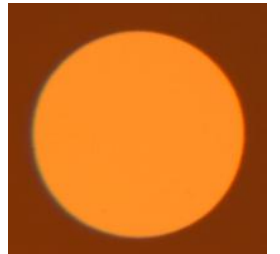

Fig. 1. A microscope image of a single metal $/ \mathrm{PdO}_{\mathrm{x}} / \mathrm{SiC}$ based diode for $\mathrm{H}_{2} / \mathrm{C}_{\mathrm{x}} \mathrm{H}_{\mathrm{y}}$ detection.

Fig. 1 shows a picture of a single $\mathrm{Pd} / \mathrm{PdO}_{\mathrm{x}} / \mathrm{SiC}$ diode fabricated using sputtering techniques. The center circle is a $\mathrm{Pd} / \mathrm{PdO}_{\mathrm{x}} / \mathrm{SiC}$ diode with radius of $500 \mu \mathrm{m}$, while the surrounding area is SiC. Testing of this diode is accomplished by mounting the diode with backside metallization $(\mathrm{Ti} / \mathrm{Ni})$ on a gold foil and making contact to both the front and back sides of the diode on a probe station. Fig. 2 is a data chart of current versus time response of a $\mathrm{Pt} / \mathrm{PdOx} / \mathrm{SiC}$ diode heated at $550^{\circ} \mathrm{C}$, biased with 
$0.3 \mathrm{~V}$, and exposed to air, $0.5 \% \mathrm{H}_{2}$ in nitrogen $\left(\mathrm{N}_{2}\right)$, and $0.5 \%$ propylene $\left(\mathrm{C}_{3} \mathrm{H}_{6}\right)$ in $\mathrm{N}_{2}$, in sequence. Although the diode has proven to perform well for hydrogen and hydrocarbon detection within a lab environment, application of the sensor in a field environment requires a transition from probe station operation to a packaged sensor operating in a real environment.

This paper discusses efforts towards integration of sensor elements such as that shown in Fig. 1 into a packaged sensor that can be used in an operational measurement system. The necessary steps toward such a packaged system include mounting the sensor onto a heater substrate, wire bonding the sensor to the substrate pad leads, and integrating the packaged sensor in an application environment for testing. An example of the challenges associated with one approach to producing a packaged $\mathrm{SiC}$ gas sensor system is presented, as well as a brief overview of other technologies involved.

In particular, wire bonding is essential for sensor packaging, therefore a bond pad for a diode is required. One approach is to use a bond pad that is isolated from the $\mathrm{SiC}$ substrate but connected with the sensing element (Fig. 3a). Compared to the diode without the pad, which only involves a straight-forward photolithography process, the fabrication of diodes with such isolated pads is more complex and takes four major steps: 1) The deposition of the $\mathrm{SiO}_{2}$ insulation layer on the whole $\mathrm{SiC}$ surface through tetraethyl orthosilicate (TEOS) thermal dissociation; 2) Back etching of a via of small diameter to expose the SiC surface for diode fabrication; 3) Deposition of the diode films $\mathrm{Pd} / \mathrm{PdO}_{\mathrm{x}}$ or $\mathrm{Pt} / \mathrm{PtO}_{\mathrm{x}}$ with larger diameter to insure all the exposed $\mathrm{SiC}$ surface is covered; and 4) Deposition of the bond pads on the TEOS that make contact with the diode.

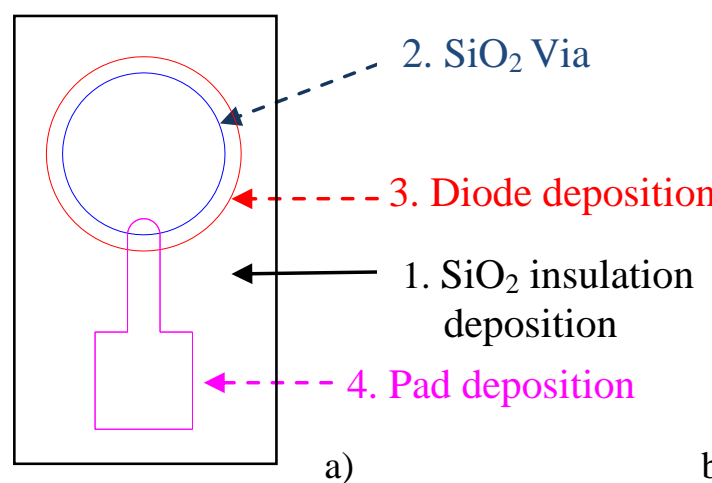

b)

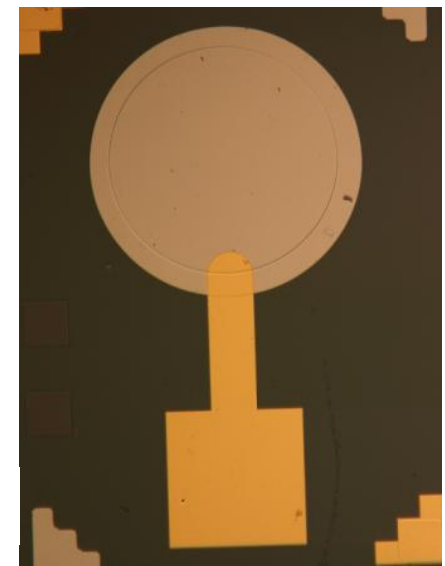

Fig. 3. Schottky diode with bond pads. a.) Drawing of a Schottky diode with a bond pad showing fabrication steps. b.) An image of a fabricated Schottky diode $\mathrm{Pd} / \mathrm{PdO}_{\mathrm{x}} / \mathrm{SiC}$ with a $\mathrm{Au} / \mathrm{Ti}$ bond pad. The dark area surrounding the sensor- pad is $\mathrm{SiO}_{2}$.

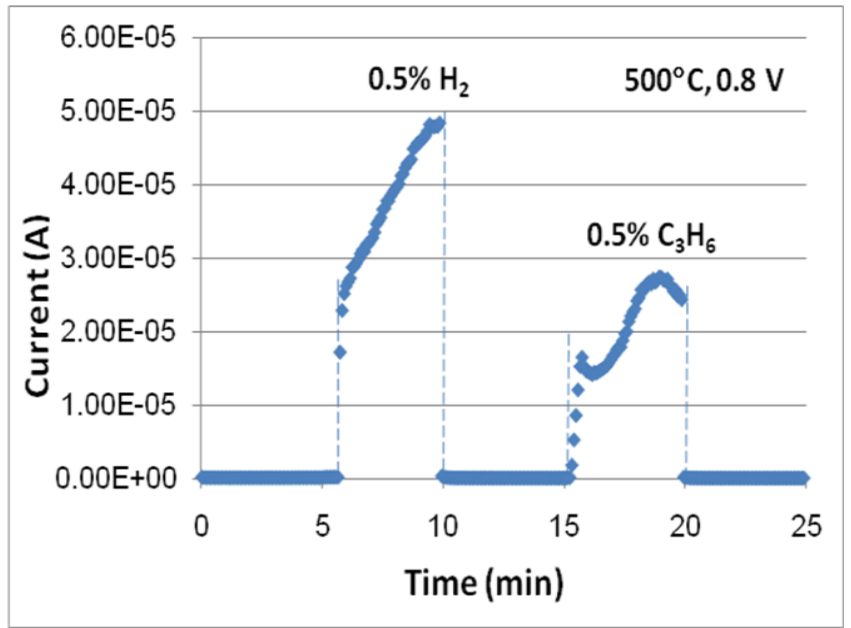

Fig. 4. Responses of a $\mathrm{Pd} / \mathrm{PdOx} / \mathrm{SiC}$ Schottky diode with $\mathrm{Pt} / \mathrm{Ti}$ bond pad to $0.5 \%$ $\mathrm{H}_{2}$ and $0.5 \% \mathrm{C}_{3} \mathrm{H}_{6}$ in $\mathrm{N}_{2}$. Air is used for the baseline.

Different materials, such as $\mathrm{Au} / \mathrm{Ti}$, $\mathrm{Pt} / \mathrm{Ti}$, and $\mathrm{Pd} / \mathrm{PdO}_{\mathrm{x}}$, were tried as bond pads. A number of samples with different contact pads were investigated. Fig. $3 b$ shows the microscope images of a fabricated $\mathrm{Pd} / \mathrm{PdO}_{\mathrm{x}} / \mathrm{SiC}$ Schottky diode with a $\mathrm{Au} / \mathrm{Ti}$ bond pad. The radii of the $\mathrm{Pd} / \mathrm{PdO}_{\mathrm{x}} / \mathrm{SiC}$ diodes range from 230 to $500 \mu \mathrm{m}$ (in Fig. 3 it is $500 \mu \mathrm{m}$ ) and the size of the pads is $600 \times 600 \mu \mathrm{m}$. A

Schottky diode $\mathrm{Pd} / \mathrm{PdO}_{\mathrm{x}} / \mathrm{SiC}$ with bond pad of $\mathrm{Pt} / \mathrm{Ti}$ was tested at $500^{\circ} \mathrm{C}$ for a prolonged time of 300 $\mathrm{hr}$. The testing was conducted on a probe station by contacting the pad. Fig. 4 is the testing result at $118 \mathrm{hr}$ showing current flow when the Schottky diode sensor is forward biased at $0.8 \mathrm{~V}$. Responses to $0.5 \% \mathrm{H}_{2}$ and $0.5 \% \mathrm{C}_{3} \mathrm{H}_{6}$ in $\mathrm{N}_{2}$ were achieved. Air, which generates a similar response as pure $\mathrm{N}_{2}$, was used for the baseline. However, the response of this sensor degraded over time. 
Although the diodes without contact pads have proven to be stable over a long period of time [1], the addition of contact pads results in a more complex sensor structure, which can cause degradation issues such as chemical reactions among film layers, and stress between different layers of the sensor structure. This is more evident at the diode and contacting pad overlap area. This area tends to have chemical reactions and deteriorate after prolonged heating. Stress caused by height difference between the $\mathrm{SiC}$ via and $\mathrm{SiO}_{2}$ surface also contributes adversely to the sensor performance. Both factors can result in decreasing of the sensor response over time and the failure of the sensor. These phenomena were observed on a number of sensors with different contact pads, such as $\mathrm{Au} / \mathrm{Ti}, \mathrm{Pt} / \mathrm{Ti}$, and $\mathrm{Pd} / \mathrm{PdO}_{\mathrm{x}}$. To better understand the reason for these failures and to study the effect of heating on a sensor structure with a bond pad, a $\mathrm{Pd} / \mathrm{PdO}_{\mathrm{x}} / \mathrm{SiC}$ diode with $\mathrm{Pt} / \mathrm{Ti}$ bond pad was heated at $600^{\circ} \mathrm{C}$ in air for more than 24 hours. Scanning electron microscopy (SEM) and Auger electron spectroscopy (AES) were used to study the sensor structure. Fig. 5a is the SEM image (400 $\mathrm{x}$ micrograph) of $\mathrm{Pd} / \mathrm{PdO}_{\mathrm{x}} / \mathrm{SiC}$ diode and $\mathrm{Pt} / \mathrm{Ti}$ connecting area. It was observed

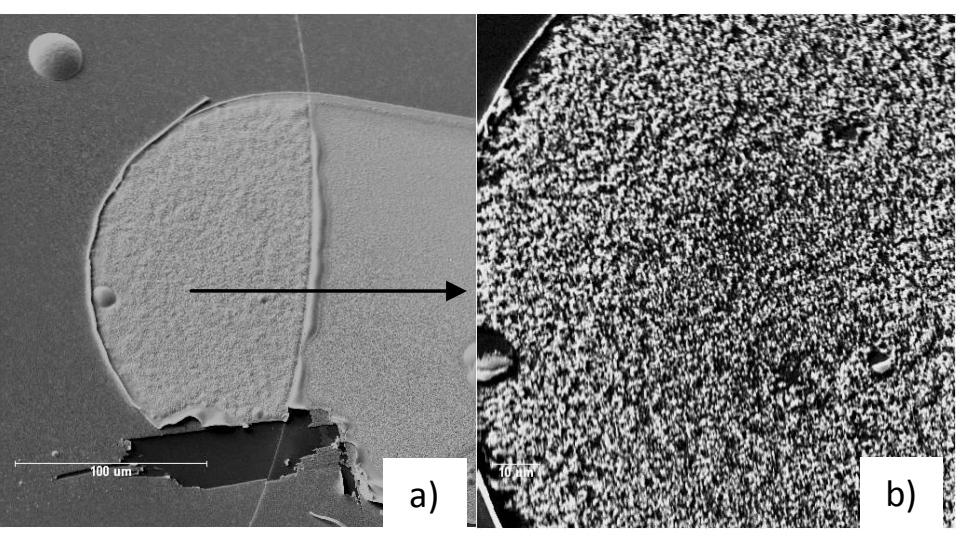

Fig. 5. a) 400x micrograph of $\mathrm{Pt} / \mathrm{Ti}$ connect on diode; b) 1000x micrograph of $\mathrm{Pt} / \mathrm{Ti}$ connection on diode. The white area is metal silicide while the dark area is $\mathrm{SiC}$.

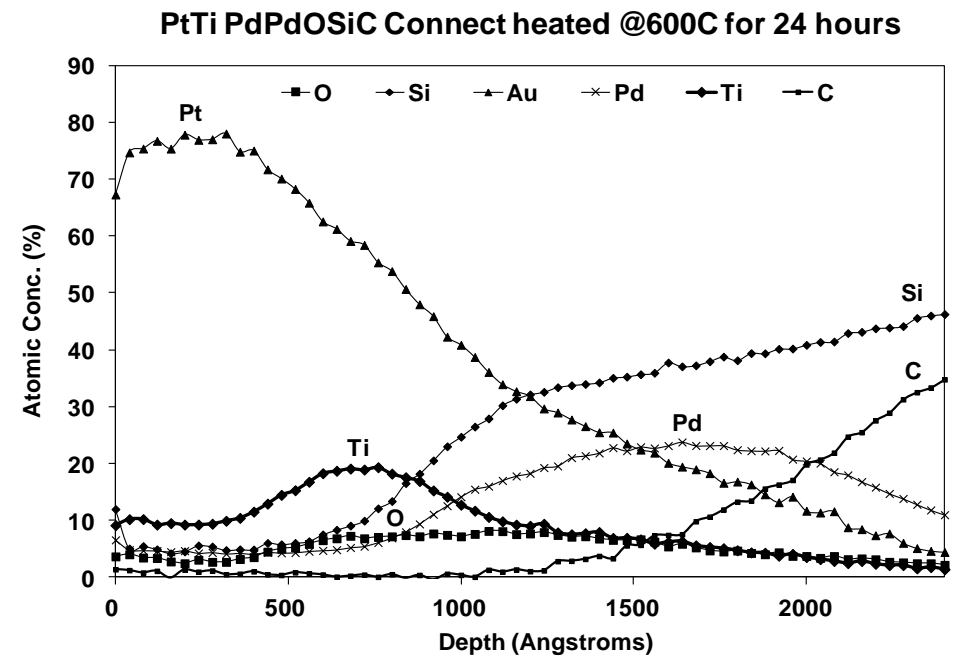

Fig. 6. Auger depth profile of the $\mathrm{Pd} / \mathrm{PdO}_{\mathrm{x}} / \mathrm{SiC}$ and $\mathrm{Pt} / \mathrm{Ti}$ connection area.

that parts of the films were missing due to the stress and peeling. Fig. 5b is the SEM image of $\mathrm{Pd} / \mathrm{PdO}_{\mathrm{x}} / \mathrm{SiC}$ and $\mathrm{Pt} / \mathrm{Ti}$ connection with $1000 \mathrm{x}$ magnification. The white area is metal silicide while the dark area is $\mathrm{SiC}$.

A point on the $\mathrm{Pt} / \mathrm{Ti}$ contact overcoating $\mathrm{Pd} / \mathrm{PdO}_{\mathrm{x}} / \mathrm{SiC}$ (Fig. 5b) was depth profiled in order to understand the chemical compositions of the films. The result in Fig. 6 indicates that the platinum has diffused through the titanium into the palladium layer. The $\mathrm{PdO}_{\mathrm{x}}$ layer $(\sim 100 \AA)$ did not provide a sufficient barrier for the platinum; the Pt diffuses through the $\mathrm{PdO}_{\mathrm{x}}$ grain boundaries and forms silicides causing a rough surface (Fig. 5b). This explains the presence of both $\mathrm{SiC}$ and $\mathrm{Pd}$ or $\mathrm{Pt}$ silicides at the substrate (Fig. 6). The Auger depth profile of the diode itself looks as expected (Fig. 7), showing a small amount of palladium oxide near the surface, preventing silicide from reaching the surface. There is a small amount of $\mathrm{SiO}_{2}$ at the interface, but it is not enough to affect the properties of the diode. In summary, the degradation of this sensor response is caused by chemical reactions among thin film layers at high temperatures and stresses due to different heights.

The above result is just one example of the development and studies of diode sensors with contact pads. The stability of the diode is consistent with what we have observed from previous work, whereas the long-term stability of the diode-pad interconnection needs improvement. It is concluded that the structure and fabrication process of the diodes with contact pads are on the right track, whereas the composition of the films for the contact pad and its compatibility with the diode film at the interconnection should be further studied and improved for long term high temperature 
stability. Film stress due to the film height difference should also be addressed. Possible improvements would be to have different pad materials, modify sensor-pad contact shapes and area, and change fabrication processes and post sensor conditioning parameters. In addition, a totally new approach, which does not isolate the bond pad from the $\mathrm{SiC}$ substrate and uses metal/ $\mathrm{PdO}_{\mathrm{x}}$ for both diode and pad, is also being attempted. This new approach has the advantage of $\mathrm{PdO}_{\mathrm{x}}$ preventing silicides formation between the gate metal and substrate for both sensor diodes and contact pads, and eliminates the depth difference between diodes and pads. The bond pad surface is to be deactivated by depositing insulator. In the future we will work on improvement of the current approach (separating pad from $\mathrm{SiC}$ using $\left.\mathrm{SiO}_{2}\right)$ and the new approach $\left(\mathrm{Pd} / \mathrm{PdO} \mathrm{x}_{\mathrm{x}}\right.$ for both diode and pad, then deactivating pad surface).

While this paper concentrates on improving the diode/contact pad interface and describing further new approach, such developments are just the first step in a range of activities necessary to transition the sensor element into an operational packaged sensor. Other related development such as sensor backside metallization, wire bonding, and packaging are being worked on in parallel. Fig. 8a shows the mounting of a Schottky diode sensor $\left(\mathrm{Pd} / \mathrm{PdO}_{\mathrm{x}}\right.$ for both sensor and $\mathrm{pad}$, pad surface not deactivated) onto a heater substrate for temperature control, and Fig. $8 \mathrm{~b}$ shows mounting of the packaged sensor (Fig. 8a) onto a probe head for measurement of emissions from aeronautic engines [3]. These parallel efforts paved the way for sensor integration into testing systems, while we continue to improve the sensor element for long-term high temperature stability.

As a summary, metal $/ \mathrm{PdO}_{\mathrm{x}} / \mathrm{SiC}$ based high temperature diode sensors with different contact pads have been investigated for packaging. Challenges related to high temperature long-term stability were studied. Future research will focused on improving chemical stability and reducing the stress of the sensor-pad connection. The sensors being improved are applicable for a variety of aerospace applications such as fuel leak detection, engine emission monitoring, and fire detection.

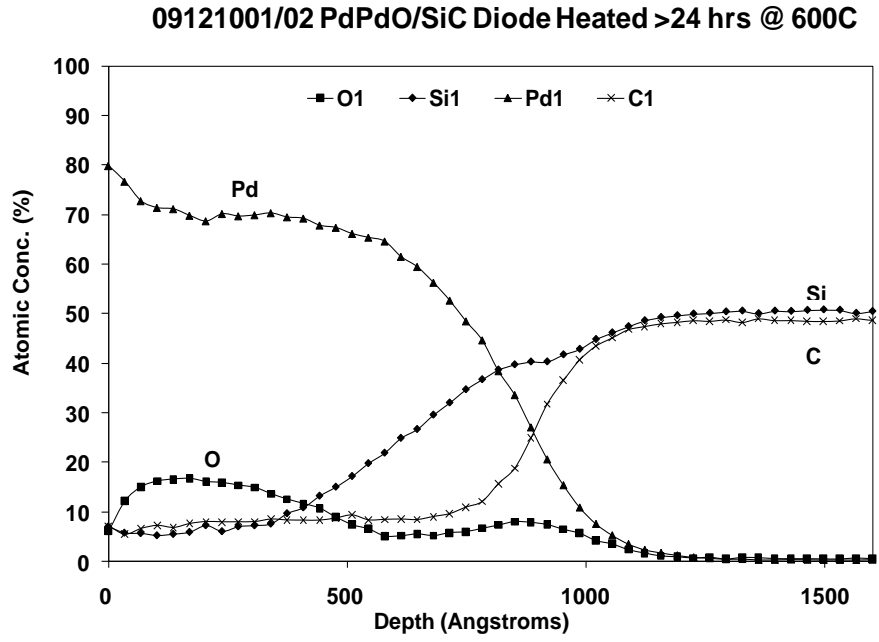

Fig. 7. Auger analysis of the diode

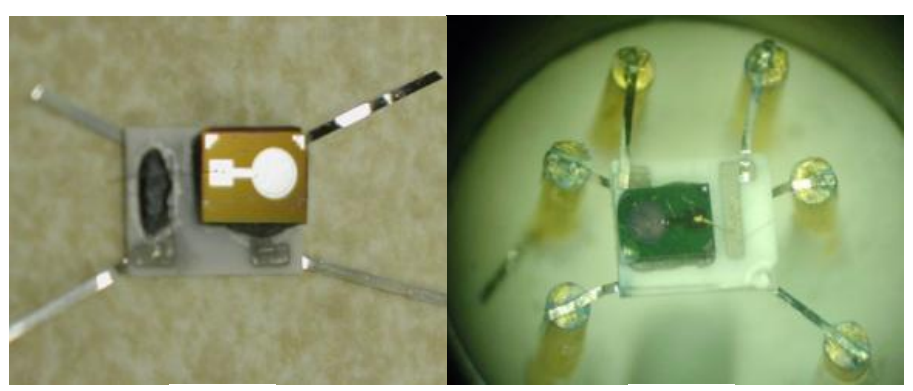

a)

Fig. 8. a) Mounting of a sensor element onto a heater substrate; b) Sensor and heater substrate mounted onto a probe head for use in emission monitoring.

Acknowledgements: B. Osborn, M. Mrdenovich, and D. Spry. Vehicle Systems Safety Technologies Project of NASA Aviation Safety Program.

\section{References:}

1. G.W. Hunter, J. C. Xu, and D. Lukco, US Patent 7,389,675B1 (2008).

2. G. W. Hunter, J. C. Xu, L. K. Dungan, B. J. Ward, S. Rowe, J. Williams, D. B. Makel, C.C. Liu, and C. W. Chang, Smart sensor systems for aerospace applications: from sensor development to application. ECS Trans., 16 (11), 333-344 (2008).

3. B. J. Ward, K. Wilcher, and G. W. Hunter, Gas microsensor array development targeting enhanced engine emissions testing. AIAA Infotech@Aerospace 2010 (Atlanta, GA, 20-22 April 2010), AIAA 2010-3327. 